\title{
Achalasia-like Changes in Eosinophilic Esophagitis
}

\author{
Teodora Surdea-Blaga ${ }^{1}$, Liliana David ${ }^{2}$, Emil-Claudiu Botan ${ }^{3}$, Dan L. Dumitrascu ${ }^{1}$
}

1) $2^{\text {nd }}$ Medical Department, Emergency Clinic Country Hospital, "Iuliu Hatieganu” University of Medicine and Pharmacy; 2) Department of Nursing, "Iuliu Hatieganu" University of Medicine and Pharmacy; 3) Department of Pathology, Emergency Clinic Country Hospital, ClujNapoca, Romania
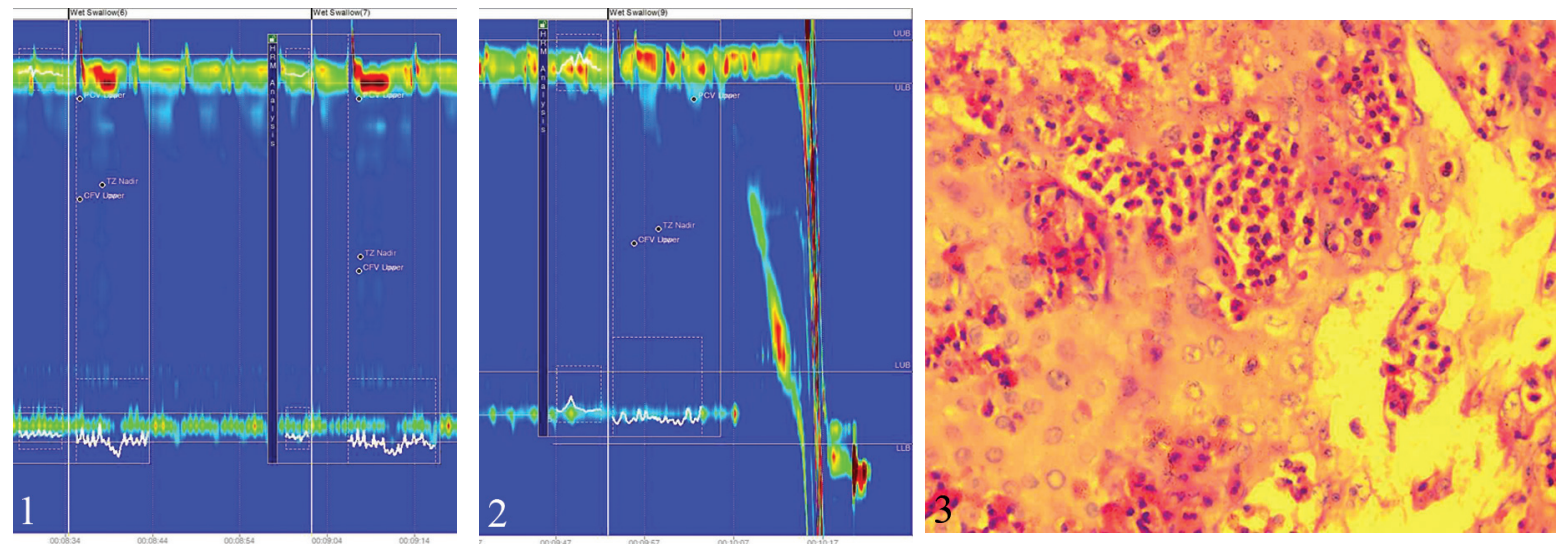

A 23-year-old female patient was referred for a high resolution esophageal manometry (HREM) for dysphagia and food impaction. Earlier, during an urgent upper gastrointestinal (GI) endoscopy for the same symptoms, an impacted food bolus was removed from the esophagus. No biopsies were taken. She had no history of allergies, gastrointestinal disorders, or medication. The HREM revealed an achalasia like pattern: normal resting lower esophageal sphincter (LES) pressure (52 $\mathrm{mmHg}$ ), increased mean integrated relaxation pressure (IRP) $(32.7 \mathrm{mmHg})$, absence of peristalsis (Fig. 1) and a pattern of normal secondary peristalsis (Fig. 2). During the $200 \mathrm{ml}$ water test, IRP was normal, without pan-esophageal pressurization. Multiple rapid swallows showed normal IRP and no peristalsis. The barium swallow test revealed normal caliber esophagus and hypoperistalsis. Upper GI endoscopy revealed multiple white spots (grade 2 exudates) along the entire esophagus [1] with 39 eosinophils/HPF, eosinophilic micro-abscesses and basal zone hyperplasia (Fig. 3) in mid esophagus biopsies. Given the food impaction history, she was diagnosed with eosinophilic esophagitis (EoE) and was started on Prednisone $25 \mathrm{mg} /$ day, tapered with $5 \mathrm{mg} /$ week. During the treatment she had no complaints, but after stopping the steroids, the dysphagia reappeared. High proton pump inhibitor doses were initiated with partial clinical response, and budesonide (as swallowed puffs from inhaler) was proposed for 6 months.

In young patients, dysphagia and food impaction should raise the concern of EoE. Eosinophilic esophagitis (prevalence 13-49 cases/100,000) is a chronic esophageal eosinophilic infiltration ( $>15$ eosinophils/HPF). The symptoms are often related to motility changes induced by inflammation: achalasia-like pattern [2], absent contractility, nutcracker esophagus or hypertensive LES. Treatment of EoE includes high
PPI doses (PPI-responsive esophageal eosinophilia), topical steroids (fluticasone or budesonide viscous preparations), or empiric six-food elimination diet. Systemic corticosteroids are an alternative when rapid improvement of symptoms is necessary, some cases requiring endoscopic dilation. A followup endoscopy (after 6-12 weeks) with esophageal biopsies is required to check the efficacy of therapy [3]. Motility changes are observed in 1/3 of EEo patients [4], but an achalasia like pattern is rarely reported.

Corresponding author: Liliana David, liliana.david@umfcluj.ro

Conflicts of interest: None to declare.

\section{REFERENCES}

1. Hirano I, Moy N, Heckman MG, Thomas CS, Gonsalves N, Achem SR. Endoscopic assessment of the oesophageal features of eosinophilicoesophagitis: validation of a novel classification and grading system. Gut 2013;62:489-495. doi:10.1136/gutjnl-2011-301817

2. Hejazi RA, Reddymasu SC, Sostarich S, McCallum RW. Disturbances of esophageal motility in eosinophilic esophagitis: a case series. Dysphagia 2010;25:231-237. doi:10.1007/s00455-009-9248-6

3. Lucendo AJ, Molina-Infante J, Arias A, et al. Guidelines on eosinophilic esophagitis: evidence-based statements and recommendations for diagnosis and management in children and adults. United European Gastroenterol J 2017;5:335-358. doi:10.1177/2050640616689525

4. Roman S, Hirano I, Kwiatek MA, et al. Manometric features of eosinophilic esophagitis in esophageal pressure topography. Neurogastroenterol Motil 2011;23:208-e111. doi:10.1111/j.13652982.2010.01633.x 